\title{
Questioning male medical circumcision: Some thoughts
}

It sounds like a fantastic deal: circumcise $80 \%$ of HIV-negative, sexually active South African (SA) men (aged 15-49), and we will all benefit from the consequent risk reduction of $60 \%$. Such a great deal that the US President's Emergency Plan for AIDS Relief (PEPFAR) intends to provide USD24 million over the 5 years from end 2017 to ramp up the effort, a nice addition to extensive funding already invested in voluntary male medical circumcision (VMMC).

The scientific case has been made, says Dr Themba Moeti, chief executive officer of the Health Systems Trust; after all, three randomised control trials in Kenya, SA (Orange Farm) and Uganda demonstrated the achievement of $60 \%$ reduced risk for heterosexual men through vaginal intercourse. ${ }^{[1-3]}$ 'In high-prevalence epidemics like ours where heterosexual transmission is the main mode of transmission driving the epidemic, MMC [male medical circumcision], if scaled up adequately, can make an important contribution to reducing HIV transmission and incidence.'

MMC is, as Morris et al. ${ }^{[4]}$ write, '... a simple, low-risk procedure with very little or no adverse long-term effect on sexual function, sensitivity, sensation during arousal or overall satisfaction. A snip that can be done at relatively low cost at community clinics - one such clinic, Asiphile, outside eThekwini in KwaZulu-Natal, Durban, having gone 'from zero circumcisions in 2010 to approximately 10,000 clients circumcised by 2012 . The follow-up rates were $87 \%$ returning for first visit and 50\% to the second; $1.8 \%$ minimal adverse events; and $88 \%$ staff retention rate - making it among the most successful VMMC services in Africa.' ${ }^{[5]}$

What's not to like about that?

Well, this is, after all, an epidemiological effort; if the targeted levels are not reached, it will not create the desired downward swing on the infection graph. And while uptake was initially good in African countries, where it was hoped that 20 million circumcisions could be achieved by 2016, as at October 2016, the numbers had reached only $56 \%$ of that. ${ }^{[6]}$

SA's goal for the national MMC programme rolled out from 2010 was 4.3 million by 2015. But as at the end of 2016, only just over 2.3 million SA men had been circumcised. ${ }^{[7]}$ Just over half the target figure has been achieved, and we're a year over the original deadline. When can we reasonably expect to hit the target - and how much more funding will we need to do so?

\section{Tracking effectiveness}

In the HIV and TB Investment Case ${ }^{[8]}$ (which looked at all possible HIV and TB interventions), says Moeti, MMC was assessed as good value. 'In the period 2011 - 2013, spending on MMC represented approximately $2 \%$ of the spending across the SA investment case categories', he says not a huge amount. But if the intervention is stalling, should we not be asking questions about how effective the programme is overall, and whether we can rejig it in some ways to make it, firstly, more appealing (to achieve better coverage) and secondly, to give us a better bang for our bucks by achieving multiple aims? Who is keeping track of the impact of the MMC campaign - not just on the new infection rate, but also on such intertwined and sensitive issues as changes (or not) in sexual behaviour, power dynamics and understandings of masculinity in a range of societal contexts, and long-term wellbeing for circumcised men and their partners?
Questions like these have been raised by academics and scientists working in other disciplines - ethnography, anthropology and psychology, for example - but focus on the push simply to perform more and more of these medical procedures has been so intense that an adversarial atmosphere has arisen - question MMC, says one academic, and you could be accused of nasty things such as being an AIDS denialist.

But people from these non-medical disciplines have some crucial insights to offer. In her unpublished article 'A living laboratory? Male medical circumcision in Swaziland, for example, Dr Nolwazi Mkhwanazi, senior lecturer (with a $\mathrm{PhD}$ in social anthropology) at the University of the Witwatersrand, identifies some instructive factors that turned a well-funded, concerted year-long drive to circumcise $80 \%$ or 152000 of the Swazi kingdom's HIV-negative males aged 15 - 49 into a damp squib. The campaign was called Soka Uncobe, but it did not 'circumcise and conquer', as the siSwati words promised. Ultimately, the campaign fizzled out with a little over $20 \%$ of its target achieved - around $32000^{[9]}$ - a result which has probably had almost no impact on the rate of infection in a country with the highest incidence level in the world.

Why did it fail?

\section{Fears and misperceptions}

'A lot of the men were afraid of becoming a statistic', Mkhwanazi said in an interview. She writes: '... many Swazi men voiced the concern that while they were aware that there was a small risk of the procedure going wrong, they feared that they would be the unlucky statistic. Some men pointed out that they simply did not want to put themselves at a risk of having a botched circumcision.'

These fears are echoed in an SA 2012 master's dissertation on perceptions around MMC back in this country: ${ }^{[10]}$ ' $\ldots$ fear of pain and medical complications were the most frequently identified barrier to MMC. Thirty percent of the sample declared that overcoming the fear of physical harm and pain was a significant challenge in their decision'

Some Swazi men did not see the value of a procedure that only offered $60 \%$ protection, writes Mkhwanazi. 'Others said that they did not see the need for men to be circumcised if after the procedure men still had to wear condoms during sexual intercourse.'

Without careful counselling to explain what is meant by a $60 \%$ reduction in risk, there may be misconceptions that lead to problems for partners. In an interview, Marion Stevens (chair: Sexual and Reproductive Justice Coalition, and research associate: African Gender Institute, University of Cape Town) offered some anecdotal evidence that at least some women whose partners have had MMC feel less safe than they did before - a misperception of the extent of the man's protection following the procedure, a feeling that 'I'm totally safe now', sometimes leading to risky behaviour that worries the woman.

Long-term, habitual shifts in sexual behaviour are key to reining in the disease: if men don't understand that they must still protect themselves and their partners after the procedure, what does this say about our long-term chances of taming HIV? Certainly there has been some off-message promotion of MMC, aimed at reeling in the young men, that could reinforce the impression that circumcision gives you freedom to 'be a player', says Prof. Catherine Burns (asso- 
ciate professor of history based at the University of Pretoria and the university's Centre for Sexualities, AIDS \& Gender).

\section{Cultural context}

A factor that the US drivers of the Soka Uncobe campaign had not anticipated was that Swazi men were curious about the fate of their foreskins. 'Early on in the campaign, rumours began circulating that the foreskins of men were going to be used to manufacture a cream that allowed people not to age', writes Mkhwanazi. 'Other rumours had it that the foreskins were being used to spice up street food which when ingested would cause impotence. When the Swazi site managers reported these rumours in the weekly meetings comprised of the various implementing partners, they were told that such rumours were absurd and would in due time die down. They did not.'

Many of the 'implementing partners' in this case were young women from the USA, Mkhwanazi points out, who dismissed the on-the-ground reports as 'superstition'.

This speaks to the importance of understanding and being sensitive to the role social, cultural and even political context plays in how effective a campaign like MMC can be. 'There's a distinction between efficacy and effectiveness,' says clinical psychologist Pierre Brouard, deputy director of the Centre for Sexualities, AIDS \& Gender. In the real world, in the hurly-burly of a push to get as many circumcised as possible, are men getting the kind of careful messaging they were given in the three trials? 'The nub of the matter is the extent to which they get all the messaging - for example, about not having sex again too soon.' And that message has to be nested within the lived context - Brouard has anecdotal evidence of men who are concerned about adhering to that prescribed break from sexual intimacy, which allows their penis to heal fully, because of concerns that 'if they don't satisfy their partner, someone else will', which means that counsellors need to address issues of intimacy between partners.

\section{Missed opportunities}

And are the medical follow-up figures quoted by Bailey et al. ${ }^{[3]}$ as good as they sound, asks Burns. After all, even the high figures achieved at Asiphile mean that 1300 men missed their first follow-up and 5000 their second.

'Medical follow-up is proving extremely expensive and complex to organise, to try and get people, who are diffusing across a whole landscape, for work, for school, for tertiary education, to get them to come back for follow-ups [...] has proven difficult for even the most motivated of programmes, she says.

How much is MMC costing us overall? 'At the average exchange rate for 2014 of ZAR10.83 = USD1, the unit cost at the 33 facilities was determined to be USD132 (ZAR1 431) per circumcision performed,' and Approximately USD14.2 million (ZAR154 million) - including funding from PEPFAR and other sources - was reported to have been spent on VMMC demand creation over the most recent 12-month period (January - December 2014) ${ }^{[111]}$ If we are spending that much, says Burns, you have to ask yourself why we are not also piggybacking on the opportunity to do 'gender sensitivity training, training around condom use and genital healthcare, and strengthening ideas about male egalitarianism' at the same time.

Why are MMC campaigns targeted, in by far the majority of cases, at men of African origin, and not South African Indians, whites and other groups, asks Burns. It is central to all public health efforts that there should be no exceptions that dilute the impact. 'People are constantly moving across "boundaries" in human sexuality', she points out. 'If you specifically leave out certain population groups, what is that based on epidemiologically? You racialise at your peril.'

\section{Traditions of masculinity}

And do the campaign messages and counselling take into account different understandings of the meaning of MMC for masculinity?

'It is currently estimated that $46.4 \%$ of all males over age 15 in South Africa have been circumcised, through either a traditional or a medical procedure. However, only $18.6 \%$ of males have been circumcised medically. ${ }^{[11]}$ More than half these SA men have therefore self-evidently been circumcised as a traditional practice, but, says Moeti, 'it is not always certain that the kind of circumcision done in some traditional settings may be effective in reducing HIV transmission risks'.

What price does it exact from communities to force them to take their boys to a mobile clinic or hospital for this procedure? 'People will see this as ripping the heart out of something that's very sacred,' says Prof. Louise Vincent (Rhodes University), whose research is largely focused on critical sexualities and women's reproductive health studies.

'What I've been arguing to the World Health Organization is that what we really need is for people to take the culture seriously and layer on to that the messages that we want to get across,' she adds.

There are social risks if it's not tackled with some thought for meanings of masculinity: '... some Xhosa men reportedly direct stigma toward those undergoing MMC, arguing that circumcisions conducted in a clinic do not confer the status of manhood, unlike the tougher traditional version long practised by Xhosa pre-initiates..[10]

It seems intuitive to bring in the traditional 'custodians of culture', both in amaXhosa culture and in others across the country, to align VMMC protocols and messages with what they are doing, rather than vice versa.

Whether it's human papillomavirus vaccination, Pap smears or HIV testing, no countrywide medical campaign can afford to ignore the lived realities of the communities it reaches - and VMMC has all sorts of points of intersection with realities that are not purely physical and 'medical'. Instead of dismissing questions about how the campaign is working as contrarian or denialist, it would surely make sense to beef up assessment, monitoring and accountability to ensure that we're getting the best impact possible.

\section{Mandi Smallhorne}

Freelance journalist and writer, Johannesburg, South Africa mandiwrite@icon.co.za

1. Auvert B, Taljaard D, Lagarde E, Sobngwi-Tambekou J, Sitta R, Puren A. Randomized, controlled intervention trial of male circumcision for reduction of HIV infection risk: The ANRS 1265 trial. PLoS Med 2005;2(11):e298. https://doi.org/10.1371/journal.pmed.0020298

2. Gray RH, Kigozi G, Serwadda D, et al. Male circumcision for HIV prevention in men in Rakai, Uganda: Aray RH, Kigozi G, Serwadda D, et al. Male circumcision for HIV prevention in men in Rakai, Uganda:
A randomised trial. Lancet 2007;369(9562):657-666. https://doi.org/10.1016/S0140-6736(07)60313-4 A randomised trial. Lancet 2007;369(9562):657-666. https://doi.org/10.1016/S0140-6736(07)60313-4
3. Bailey RC, Moses S, Parker CB, et al. Male circumcision for HIV prevention in young men in Kisumu, Bailey RC, Moses S, Parker CB, et al. Male circumcision for HIV prevention in young men in Kisumu,
Kenya: A randomized control trial. Lancet 2007;369(9562):643-656. https://doi.org/10.1016/S01406736(07)60312-2

4. Morris BJ, Bailey RC, Klausner JD, et al. Review: A critical evaluation of arguments opposing male circumcision for HIV prevention in developed countries. AIDS Care 2012;24(12):1565-1575. https:// doi.org/10.1080/09540121.2012.661836

5. Schenker I, Westreich M. Voluntary medical male circumcision: A necessary surgical intervention in curbing HIV/AIDS. RCS Bull 2015;97(9):378-381. https://doi.org/10.1308/rcsbull.2015.378

6. AVERT. Understanding the barriers to circumcision in southern and eastern Africa. 25 October 2016. https://www.avert.org/news/understanding-barriers-circumcision-southern-and-eastern-africa (accessed 6 June 2017)

7. Medical Brief. PEPFAR commits USD24 million to accelerating MMC efforts in SA. 7 December 2016. http://www.medicalbrief.co.za/archives/pepfar-commits-24m-accelerating-mmc-efforts-sa/ (accessed 6 June 2017).

8. Department of Health, South Africa, and South African National AIDS Council. South African HIV and TB Investment Case - Summary Report Phase 1. March 2016. http://sanac.org.za/wp-content/ uploads/2016/03/1603-Summary-Report-LowRes-18-Mar.pdf (accessed 6 June 2017).

9. Irin News. Circumcision plans go awry in Swaziland. 13 May 2013. http://www.irinnews.org/ . Irin News. Circumcision plans go awry in
news/2013/05/13 (accessed 6 June 2017).

10. Mathew W. Cutting into perceptions: Investigating men's understanding of protection - through medical male circumcision for HIV prevention, in Durban, KwaZulu-Natal. MSocSci dissertation. Durban: University of KwaZulu-Natal, November 2012.

11. Tchuenche M, Palmer E, Haté V, et al. The cost of voluntary medical male circumcision in South Africa. PLoS One 2016;11(10):e0160207. https://doi.org/10.1371/journal.pone.0160207 